\title{
Health-related quality-of-life measures for long-term follow-up in children after major trauma
}

\author{
Loes Janssens · Jan Willem Gorter • \\ Marjolijn Ketelaar • William L. M. Kramer • \\ Herman R. Holtslag
}

Accepted: 30 March 2008/Published online: 24 April 2008

(C) The Author(s) 2008

\begin{abstract}
Objective Our objective was to review measures of health-related quality of life (HRQL) for long-term follow up in children after major trauma and to determine the measures that are suitable for a large age range, reliable and valid, and cover a substantial amount of the domains of functioning using the International Classification of Functioning, Disability, and Health (ICF) of the World Health Organization (WHO).

Methods The Medline and EMBASE databases were searched in all years up to October 2007 for generic HRQL measures suitable for children aged 5-18 years old and validated in English or Dutch. Measures were reviewed with respect to the age range for which the measure was suitable and reliability, validity, and content related to the ICF.
\end{abstract}

L. Janssens · H. R. Holtslag ( $₫)$

Department of Rehabilitation and Sports Medicine, University

Medical Center Utrecht, PO Box 85500, HP F00.810, 3508 GA

Utrecht, The Netherlands

e-mail: h.r.holtslag@umcutrecht.nl

L. Janssens - J. W. Gorter - M. Ketelaar

Center of Excellence for Rehabilitation and Sports Medicine Utrecht, Rehabilitation Center 'De Hoogstraat' Utrecht, Utrecht,

The Netherlands

J. W. Gorter · H. R. Holtslag

Rudolf Magnus Institute of Neuroscience of the University

Medical Center Utrecht, Utrecht, The Netherlands

W. L. M. Kramer

Department of Pediatric Surgery, University Medical Center

Utrecht, Utrecht, The Netherlands

W. L. M. Kramer

Department of Pediatric Traumatology, University Medical

Center Utrecht, Utrecht, The Netherlands
Results The search resulted in 1,235 hits and 21 related articles. Seventy-nine papers met the inclusion criteria, describing in total 14 measures: Child Health and Illness Profile Adolescent and Child Edition (CHIP-AE/CE), Child Health Questionnaire Child and Parent Forms (CHQCF87/PF50/PF28), DISABKIDS, Functional Status II (FS II)(R), Health Utilities Index Mark 2 (HUI 2), KIDSCREEN 52/27, KINDL, Pediatric Quality of Life Inventory (PedsQL), TNO Institute of Prevention and Health and the Leiden University Hospital (TNO-AZL), TNO-AZL Children's Quality Of Life (TACQOL), and Youth Quality of Life Instrument-Research Version (YQOL-R). Measures that were suitable for a large age range were CHQ-PF50/PF28, DISABKIDS, FS II(R), HUI 2, KIDSCREEN, PedsQL, and TACQOL. All measures had moderate to good psychometric properties, except for CHQ-PF50/PF28, KINDL, and TACQOL, which had either low internal consistency or bad test-retest reliability. The measures that covered more than six chapters of the ICF domains were CHIP-AE/CE, CHQ-CF87/PF50, DISABKIDS, KIDSCREEN-52, PedsQL, and TACQOL.

Conclusions DISABKIDS, KIDSCREEN 52, and PedsQL are suitable for long-term follow-up measurement of HRQL in children after major trauma. They cover a large age range, have good psychometric properties, and cover the ICF substantially.

Keywords Health-related quality of life - Children . Major trauma - Long term - International classification of functioning $\cdot$ Disability and health

$\begin{array}{ll}\text { Abbreviations } \\ \text { CHIP-AE } & \begin{array}{l}\text { Child Health and Illness Profile Adolescent } \\ \text { Edition }\end{array} \\ \text { CHIP-CE } & \text { Child Health and Illness Profile Child Edition }\end{array}$




$\begin{array}{ll}\text { CHQ-CF } & \text { Child Health Questionnaire Child Form } \\ \text { CHQ-PF } & \begin{array}{l}\text { Child Health Questionnaire Parent Form } \\ \text { HRQL }\end{array} \\ \text { Health Related Quality of Life } \\ \text { HUI 2 } & \begin{array}{l}\text { Health Utilities Index Mark 2 } \\ \text { ICF }\end{array} \\ & \begin{array}{l}\text { International Classification of Functioning, } \\ \text { Disability, and Health }\end{array} \\ \text { PedsQL } & \text { Pediatric Quality of Life Inventory } \\ \text { TACQOL } & \text { TNO-AZL Children's Quality Of Life } \\ \text { YQOL-R } & \begin{array}{l}\text { Youth Quality of Life Instrument-Research } \\ \text { Version }\end{array} \\ \text { WHO } & \text { World Health Organization }\end{array}$

\section{Introduction}

Injuries are a leading cause of death in children of 118 years of age $[1,2]$. The survival rate of major traumatized children is about $80 \%$ [2, 3]. Injuries can cause severe functional impairment and psychosocial problems in the short term and long term [4-9]. Despite the prominent role of major trauma in mortality and morbidity in children, relatively little research has been done in terms of quality of life of children after major trauma. Most studies focus on the consequences of brain injury [10-12], whereas the quality of life in pediatric major trauma remains relatively unexplored. Van der Sluis and colleagues described the long-term outcome in pediatric polytrauma patients in 1997 [13]. Nine years after trauma, the RAND-36 was administered to patients 18 years of age or older. The quality of life enjoyed by the patients did not differ from a healthy reference population. Holbrook et al. recently studied the quality of life in adolescents 3, 6, 12, 18, and 24 months after major trauma with the Quality of Well-being Scale [14]. Significant deficits in quality of well-being were found in adolescents after major trauma compared with US norms for healthy adolescents.

There are many terms used to describe quality of life in health care, for example: health-related quality of life (HRQL), well-being, health status, and functional status. In this review, the definition of HRQL as described by the World Health Organization (WHO) is adopted. The WHO defines HRQL as the individuals' perception of their position in life in the context of culture and value systems in which they live, and in relation to their goals, expectations, standards, and concerns [15]. To study HRQL in pediatric trauma patients, first a decision has to be made about what measure to use. Currently, many HRQL measures for children are available. Some measures are disease specific, whereas others are generic. Unfortunately, no trauma-specific HRQL measure has been developed for children, leaving generic measures as first choice.
Comparison of the available measures enables a wellconsidered decision.

The aim for this review is to provide an overview of the available measures of HRQL for long-term follow-up in children after major trauma so that measures can be selected that are suitable for a large age range, valid and reliable, and cover a substantial amount of the content of the International Classification of Functioning, Disability, and Health (ICF) of the WHO [16].

\section{Methods}

Literature search

Medline and EMBASE databases were searched in all years up to October 2007 for measures of HRQL in children. The following search was entered: [(child* OR pediatr* OR paediatr* OR adolesc*) AND (quality of life OR health status) AND (psychometr* OR validity OR reliability OR cronbach OR test-retest)]. In Medline the extension (Title/abstract) was added to all terms to specify the search. Inclusion criteria were: (1) validation study of a generic HRQL measure in children in a Western country, (2) the measure is suitable for children in the age range of 5-18 years, (3) the paper is written in English or Dutch, (4) the measure has an English or Dutch version, (5) the measure has both validity and reliability reported.

Measure comparison

The measures were reviewed on four levels: (1) age range, (2) reliability, (3) validity, and (4) the content related to the ICF. The underlying idea for the measure comparison on these four levels is as follows:

\section{Age range}

When a measure is suitable for a large age range, fewer measures are needed to study a cohort. Therefore, a better comparison can be made over time and between subjects of different ages. In this review, a large age range is defined as at least 10 years covered. Measures were selected that were suitable for children who were $>5$ years old, because it is hypothesized that 5 years after trauma the most recovery that can be expected has taken place and that the child is in a relatively stable situation. Some measures have different versions for different age categories. When these versions were similar in content, the age ranges of these different versions were added. When they had a different amount of questions or a different scoring system, the versions were considered as separate measures and the age ranges were not added. 


\section{Reliability}

On the second level, the internal consistency and the testretest reliability of the HRQL measures were compared. In this review, a measure was considered reliable when it reached at least group comparison level for internal consistency (Cronbach's alpha $>0.70$ ), [17] and had a substantial test-retest reliability [kappa, intraclass correlation coefficients (ICC), Spearman or Pearson correlation coefficient $>0.60$ ] [18]. A measure was found reliable when at least $80 \%$ of the measurements of reliability exceeded the set levels.

\section{Validity}

Comparison of the validity of a measure is a complicated matter, because there are many ways to describe it. Validity can be divided into content and construct validity. A method often used to describe content validity of an HRQL measure is the ability to differentiate between healthy subjects and children with a disease. Construct validity can be described, for example, by factor analysis, by the correlation of a measure with other instruments that aim to measure similar or different constructs, and by the correlation with preknown information or clinical symptoms. In this review, an attempt was made to give an overview of the content and construct validity for all included HRQL measures.

\section{Content related to the ICF}

The fourth and final level of comparison included the content of the questionnaires. This comparison was made in light of the ICF [16] (Fig. 1). It is a model in which health condition is defined by three domains: body functions and structures, activities, and participation. These domains are divided into chapters, as listed in Table 5. To compare the content of the questionnaires, all items were placed in one of the ICF chapters. If an item encompassed different constructs, the item was placed in more than one chapter. For example, the fourth item of the Health Utilities Index Mark 2 (HUI 2) "Learns and remembers school work normally for age," encompassed two constructs: "learn" and "remember." These two constructs were placed in two different chapters, namely, the first chapter of activities and participation and the first chapter of body functions and structures, respectively. If the content of the item did not fit in one of the chapters, the item was placed in the category "other".

Placement of items in the chapters of the ICF was done by three researchers independently. One of them (LJ) placed the items of all measures, whereas the other two (MK and MB) placed the items of seven measures. So finally, all items were placed by two researchers. In case of disagreement, a discussion followed, led by a fourth

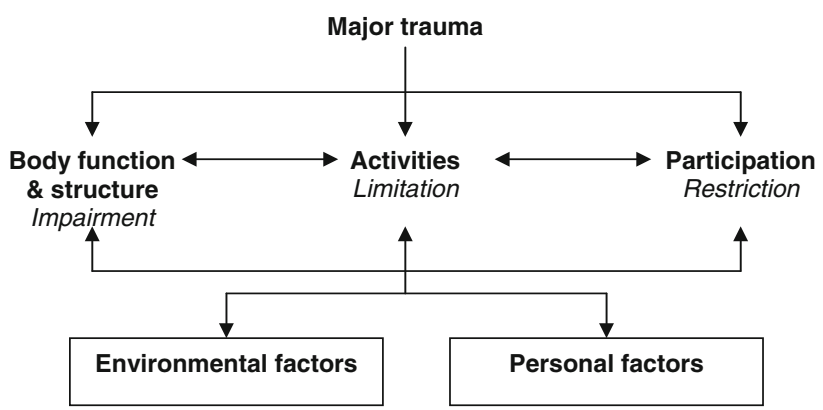

Fig. 1 International Classification of Functioning, Disability and Health (ICF) of the World Health Organization (WHO) [12]

independent person (JWG). This person finally decided in which ICF chapter the item was placed. The number of chapters covered by the items was used as a measure for covering the ICF. In this review, a measure was found to represent the ICF substantially when the items covered more than six chapters.

\section{Results}

The search in Medline and EMBASE databases rendered 1,235 hits and 21 related articles. Seventy-nine papers met the inclusion criteria, describing in total 14 measures. The number of references per measure varied between 1 and 26 . The included measures are Child Health and Illness Profile Adolescent and Child Edition (CHIP-AE [19-21], CHIPCE [22, 23]), Child Health Questionnaire Child and Parent Forms (CHQ-CF87 [24-30], CHQ-PF50 [26, 27, 30-53], CHQ-PF28 [54-57]), DISABKIDS [58, 59], Functional Status II (FS II)(R) [60, 61], HUI 2 [32, 52, 62-64]), KIDSCREEN 52 [65, 66] and KIDSCREEN 27 [67, 68], KINDL [25, 69-72], Pediatric Quality of Life Inventory 4.0 (PedsQL [10, 73-91]), TNO-AZL Child Quality of Life questionnaire (TACQOL [92-95]), and Youth Quality of Life Instrument-Research Version (YQOL-R [96]).

Comparison of the age range and other general characteristics

CHIP, CHQ, DISABKIDS, KIDSCREEN, PedsQL, and TACQOL have different versions for different age categories. Besides language adaptations, the age-adapted versions of CHIP and CHQ also have different numbers of items and different scoring systems. Therefore, the child and adolescent edition of CHIP and the child and parent form of CHQ were considered as separate measures. The number of items and the scoring system of the different versions of DISABKIDS, KIDSCREEN, PedsQL, and TACQOL are similar. Therefore, these versions were considered as one measure, and the age ranges are added. 
The measures that are suitable for the largest age range are HUI 2 and PedsQL. They are both validated for children between 2 and 18 years old. CHQ-PF50/28 (5-18 years), DISABKIDS (4-16 years), FS II(R) (0-12 years), KIDSCREEN 52/27 (8-18 years), and TACQOL (6-15) are also validated for an age range of 10 years or more. Measures suitable for an age range of less than 10 years are CHIP-AE/ CE (11-17 / 6-11 years), YQOL-R (12-18 years), CHQ-CF (10-18 years), and KINDL (8-16 years). The large age range measures are all proxy reported or clinician administered, except for PedsQL, DISABKIDS, KIDSCREEN, and TACQOL, which also have a self-report version. The minimal age limit used for self-report measures varies between 8 and 11 years. The proxy-report measures and the clinicianadministered measures are suitable for children of all ages.

The number of items varies enormously for each measure. HUI 2 contains less than ten items, whereas CHIP-AE and TACQOL contain more than 100 items, resulting in large differences in the time needed to complete the questionnaire. Short measures take only $5 \mathrm{~min}$ or less, whereas the larger measures take 10-45 min to complete. Measures that take 20 min or more to complete were CHIP$\mathrm{AE} / \mathrm{CE}$ and CHQ-CF87/PF50. Items are placed in a varying number of domains, with a median of six domains. PedsQL and YQOL-R have only four domains, whereas $\mathrm{CHQ}$ has 13 domains. General characteristics of all measures are summarized in Tables 1 and 2 .

\section{Comparison of reliability}

Internal consistency for the total score is reported for FS II(R), KINDL, PedsQL, and YQOL-R. In KINDL, PedsQL proxy-report version, and YQOL-R, all Cronbach alphas for the total score exceeded the 0.70 level of group comparison. In the PedsQL self-report version and in FS II(R), $95 \%$ and $63 \%$ of the alphas for the total score were $>0.70$, respectively. Internal consistency for the domains is reported for all measures except for HUI 2. In CHIP-AE/ CE, DISABKIDS, FS II(R), KIDSCREEN 52/27, and YQOL-R, all alphas for the domains exceeded the 0.70 level. Measures with nearly all alphas for the domains $>0.70$ were CHQ-CF/PF50 (93\% and 86\%) and the proxyand self-report version of PedsQL (95\% and 84\%). Measures with $<80 \%$ of alphas for domains $>0.70$ were TACQOL (69\%), CHQ-PF28 (53\%), and KINDL (33\%).

ICC, Pearson correlation coefficients, and kappas were used to report test-retest reliability in the reviewed articles. Test-retest reliability for the total score is reported for FS II(R), HUI 2, PedsQL, and YQOL-R. All measured coefficients for the total score exceeded the 0.60 level. Testretest reliability for the domains is reported for all measures except for FS II(R), KIDSCREEN 52, KINDL, and PedsQL self-report version. All coefficients for the testretest reliability of the domains exceeded the 0.60 level for CHIP-AE/CE, DISABKIDS, KIDSCREEN 27, PedsQL proxy-report version, and YQOL-R. HUI 2 has $80 \%$ of its reported coefficients $>0.60$. Measures with $<80 \%$ of coefficients $>0.60$ were TACQOL (73\%), CHQ-PF50 (65\%), CHQ-CF87 (60\%), and CHQ-PF28 (50\%). Reliability for all measures is summarized in Table 3.

\section{Comparison of validity}

Validity was assessed and reported differently in all studies, so a comparison was difficult to make. For most measures, content validity was assessed by the ability to

Table 1 General characteristics of health-related quality of life (HRQL) measures in children: number and titles of the domains

\begin{tabular}{|c|c|c|}
\hline Measure & \multicolumn{2}{|c|}{ Number and titles of the domains } \\
\hline CHIP-AE & 6 & Discomfort, disorders, satisfaction with health, achievement, risks, resilience \\
\hline CHIP-CE & 5 & Satisfaction, comfort, risk avoidance, resilience, achievement \\
\hline $\begin{array}{l}\text { CHQ-CF87 } \\
\text { CHQ-PF50 } \\
\text { CHQ-PF28 }\end{array}$ & 13 & $\begin{array}{l}\text { Physical functioning, role functioning: emotional/behavioral, role functioning: physical, bodily pain, general } \\
\text { behavior, mental health, self-esteem, general health perceptions, parental impact: emotional, } \\
\text { parental impact: time, family activities, family cohesion, change in health }\end{array}$ \\
\hline DISABKIDS & 6 & Independence, physical limitation, emotion, social inclusion, social exclusion, treatment \\
\hline FS II (R) & 8 & Communication, mobility, mood, energy, play, sleep, eating, toileting \\
\hline HUI 2 & 6 & Sensation, mobility, emotion, cognition, self-care, pain \\
\hline KIDSCR-52 & 10 & $\begin{array}{l}\text { Physical well-being, psychological well-being, moods \& emotions, self perception, autonomy, } \\
\text { parent relation and home life, peers and social support, school environment, bullying, financial resources }\end{array}$ \\
\hline KIDSCR-27 & 5 & Physical well-being, psychological well-being, parent relations \& autonomy, social support \& peers, school environment \\
\hline KINDL & 6 & Physical health, general health, family functioning, self-esteem, social functioning, school functioning \\
\hline PedsQL4.0 & 4 & Physical functioning, emotional functioning, social functioning, school functioning \\
\hline TACQOL & 7 & Pain and symptoms, basic motor functioning, social functioning, school functioning \\
\hline YQOL-R & 4 & Self, relationships, environment, general quality of life \\
\hline
\end{tabular}


Table 2 General characteristics of health-related quality of life (HRQL) measures in children: validated age range, how to report, rating scale, number of items, time needed to complete the measure

\begin{tabular}{lcllcc}
\hline Measure & Age in years & Report & Rating scale & Number of items & Time in minutes \\
\hline CHIP-AE & $11-17$ & Self & 3 to 5 point Likert scale & 107 & 45 \\
CHIP-CE & $6-11$ & Proxy & 3 to 5 point Likert scale & 76 & 20 \\
CHQ-CF87 & $10-18$ & Self & 4 to 6 point Likert scale & 87 & 20 \\
CHQ-PF50 & $5-18$ & Proxy & 4 to 6 point Likert scale & 50 & 20 \\
CHQ-PF28 & $5-18$ & Proxy & 4 to 6 point Likert scale & 28 & $5-10$ \\
DISABKIDS & $4-16$ & Proxy or self & 5 point Likert scale & 37 & 10 \\
FS II (R) & $0-12$ & Proxy & 3 point Likert scale & 14 & 10 \\
HUI 2 & $2-18$ & Clinician or proxy & Ordinal classification system & 6 & $<5$ \\
KIDSCR-52 & $8-18$ & Proxy or self & 5 point Likert scale & 52 & $15-20$ \\
KIDSCR-27 & $8-18$ & Proxy or self & 5 point Likert scale & 27 & $10-15$ \\
KINDL & $8-16$ & Self & 5 point Likert scale & 24 & $5-10$ \\
PedsQL4.0 & $2-18$ & Proxy or self & 3 or 5 point Likert scale & 23 & $5-10$ \\
TACQOL & $6-15$ & Proxy or self & 3 and 4 point Likert scale & 108 & 10 \\
YQOL-R & $12-18$ & Self & 11 point Likert scale & 41 & $10-15$ \\
\hline
\end{tabular}

differentiate between healthy subjects and children with a disease. All measures were able to do so in a variety of diseases, except for KINDL, which could not differentiate between healthy and chronically ill children. No information about content validity was reported for CHIP-CE and KIDSCREEN 52. Construct validity was assessed by factor analysis, by correlation with other instruments that aim to measure similar or different constructs, and by correlation with preknown information or clinical symptoms. Factor analysis was performed for CHIP-AE/CE, CHQ-PF50, KIDSCREEN 27, KINDL, PedsQL, and TACQOL and revealed that most items of these measures load most

Table 3 Internal consistency and test-retest reliability for health-related quality of life (HRQL) measures in children

\begin{tabular}{|c|c|c|c|c|c|}
\hline \multirow[t]{2}{*}{ Measure } & \multirow[t]{2}{*}{ Total, domain, subdomain } & \multicolumn{2}{|c|}{ Internal consistency } & \multicolumn{2}{|l|}{ Test-retest } \\
\hline & & Cronbach $\alpha$ & $>0.70(\%)$ & ICC, $\kappa$, Pearson & $>0.60(\%)$ \\
\hline CHIP-AE & Domain & $0.79-0.92$ & 100 & $0.74-0.93$ & 100 \\
\hline CHIP-CE & Domain & $0.70-0.88$ & 100 & $0.63-0.85$ & 100 \\
\hline CHQ-CF87 & Domain & $0.54-0.97$ & 93 & $0.06-0.84$ & 60 \\
\hline CHQ-PF50 & Domain & $0.39-0.97$ & 84 & $-0.30-1.00$ & 65 \\
\hline CHQ-PF28 & Domain & $0.07-0.88$ & 53 & $0.14-0.75$ & 50 \\
\hline DISABKIDS & Domain & $0.70-0.90$ & 100 & $0.71-0.83$ & 100 \\
\hline \multirow[t]{2}{*}{ FS II(R) } & Total & $0.56-0.91$ & 63 & $0.60-0.92$ & 100 \\
\hline & Domain & $0.83-0.93$ & 100 & & \\
\hline \multirow[t]{2}{*}{ HUI 2} & Total & & & 0.90 & 100 \\
\hline & Domain & & & $0.55-1.00$ & 80 \\
\hline KIDSCR-52 & Domain & $0.76-0.90$ & 100 & & \\
\hline KIDSCR-27 & Domain & $0.78-0.84$ & 100 & $0.61-0.74$ & 100 \\
\hline \multirow[t]{2}{*}{ KINDL } & Total & $0.71-0.95$ & 100 & & \\
\hline & Domain & $-0.19-0.89$ & 33 & & \\
\hline \multirow[t]{2}{*}{ PedsQL4.0 proxy-report } & Total & $0.74-0.94$ & 10 & $0.78-0.88$ & 100 \\
\hline & Domain & $0.59-0.93$ & 95 & $0.75-0.91$ & 100 \\
\hline \multirow[t]{2}{*}{ PedsQL4.0 self-report } & Total & $0.66-0.92$ & 97 & 0.86 & 100 \\
\hline & Domain & $0.39-0.90$ & 84 & & \\
\hline TACQOL & Domain & $0.55-0.95$ & 69 & $0.30-0.91$ & 73 \\
\hline \multirow[t]{2}{*}{ YQOL-R } & Total & $0.94-0.96$ & 100 & 0.78 & 100 \\
\hline & Domain & $0.77-0.99$ & 100 & $0.74-0.85$ & 100 \\
\hline
\end{tabular}


highly on their conceptually derived scale. A summary of the information on content and construct validity for all measures is reported in Table 4.

\section{Covering the ICF}

Measures that covered more than six chapters of the ICF domains were CHIP-AE/CE, CHQ-CF87/PF50, DISABKIDS, KIDSCREEN 52, PedsQL, and TACQOL. CHQ-PF, HUI 2, and KIDSCREEN-27 covered six chapters; YQOL$\mathrm{R}$ covered five chapters; KINDL covered four chapters, and FS II(R) covered three chapters. CHIP-AE covered the ICF domain body functions \& structures best, with all chapters represented in the measure. Only one to four of the chapters of body functions \& structures were covered by the other measures. CHIP-AE/CE, CHQ-CF87, and TACQOL covered ICF domains activities and participation best, with seven of nine chapters represented in the measures. Measures with less than half of the chapters of activities and participation covered were CHQ-PF28, FS II(R), HUI 2, KINDL, and YQOL-R (see Table 5).

\section{Discussion}

The 14 measures that resulted from the literature search performed differently on all four aspects that were looked at in this review. Measures that performed best on one level were outperformed on other levels and vice versa. For the purpose of this review, a measure should meet the criteria on all four aspects to be found suitable in measuring HRQL in children after major trauma. Most measures met the first criterion: "suitable for an age range of at least 10 years." Measures that did not meet this criterion were CHIP-AE/ CE, CHQ-CF87, KINDL, and YQOL-R. The second criterion was group comparison level for the internal consistency $(\alpha>0.70)$ and substantial test-retest reliability (kappa, ICC, Spearman or Pearson correlation coefficient $>0.60$ ) in at least $80 \%$ of the measurements of reliability. Measures that did not meet this criterion were CHQ-CF87/PF50/PF28, FS II(R), KINDL, and TACQOL. The third aspect looked at was the content and construct validity of the measures, which was confirmed for all measures. The fourth and final criterion was that the items covered more than six chapters of ICF domains. This criterion was met by all measures except for CHQ-PF28, FS II(R), HUI 2, KIDSCREEN-27, KINDL, and YQOL-R. So the measures that met all four criteria were DISABKIDS, KIDSCREEN 52, and PedsQL4.0.

Two earlier reviews also came to a recommendation after comparing the general characteristics and psychometric properties of pediatric HRQL measures. Willis et al. assessed outcome measures in pediatric trauma populations
[97]. They recommended PedsQL 4.0 for children $>2$ years of age because it captured both functional and QOL information, was quick to administer, covered a large age range, and had a self- and parent-proxy-report version. Eiser et al. reviewed generic and disease-specific measures of QOL in 2001 [98]. They recommended PedsQL for brief assessment during a regular clinic visit and CHQ where the goal is to improve family functioning or school integration. Other measures that performed well in current review: DISABKIDS and KIDSCREEN 52, were unfortunately not included in these two earlier reviews. In 2007, the European Consumer Safety Association (ECSA) developed guidelines for the conduction of follow-up studies measuring injury-related disability [99]. They chose EuroQoL5D (EQ-5D) in combination with HUI 3 as the preferred common core to measure functional outcome after injury in patients aged 5 years or older. The ECSA assessed the content of the measures related to ICF domains. However, the psychometric properties of the measures were not considered. EQ-5D and HUI 3 were not included in this review because the measures were developed for adults and have not yet been sufficiently validated in children.

Strengths and limitations

The two largest biomedical databases (Medline and EMBASE) were searched for validation studies of HRQL measures for children. Despite the extensive search strategy, some relevant related articles were not found initially. Perhaps the addition of more synonyms for quality of life could have overcome this limitation. Another option is to search more databases, for example, the psychological database PsycINFO. However, it seems that no measures were missed. The pediatric HRQL measures included in the most recent review articles corresponded mostly with the measures that were included in this review [97, 100-102]. The How are You (HAY) was excluded because it also contained disease-specific questions. The Exeter HRQL and the Generic Child Questionnaire (GCQ) were excluded because psychometric properties were reported insufficiently. No measures were included that had not been reviewed previously.

The articles were screened for meeting the inclusion criteria. Because no trauma-specific HRQL measure is available for children, generic measures were selected. To make comparison of psychometric properties possible, only measures were included for which validity and reliability was reported. Results were limited to validation studies performed in Western countries, because culture is hypothesized to have a great impact on the psychometric properties of the measure. Only measures that have an English or Dutch version were included, because the English language is most used in Western society, and 
Table 4 Content and construct validity for health-related quality of life (HRQL) measures in children

\begin{tabular}{ll}
\hline Measure & $\begin{array}{l}\text { Content validity } \\
\text { Differentiates health } \& \text { disease }\end{array}$ \\
\hline CHIP-AE & $\begin{array}{l}\text { Healthy } \neq \text { illness } \\
\text { School population } \neq \text { illness }\end{array}$ \\
CHIP-CE & Healthy $\neq$ major chronic illness \\
& \\
CHQ-CF87 & $\begin{array}{l}\text { Healthy } \neq \text { illness } \\
\text { Norm } \neq \text { diabetes }\end{array}$ \\
& Healthy $\neq$ chronic health condition \\
CHQ-PF50 & $\begin{array}{l}\text { Norm } \neq \text { diabetes } \\
\text { Norm } \neq \text { diabetes }\end{array}$ \\
& Healthy $\neq$ chronic health condition \\
& Healthy $\neq$ HIV \\
Healthy $\neq$ chronic health condition \\
Healthy $\neq$ severe health condition
\end{tabular}

FS II(R)

HUI 2

KIDSCR-52 ?

KIDSCR-27 Healthy $\neq$ physically ill

Healthy $\neq$ mentally ill

KINDL

Healthy $\neq \mathrm{DM}$

Healthy $=$ chronically ill

PedsQL4.0 Healthy $\neq$ chronic health condition (CP, ADHD, headache, asthma,

$\mathrm{DM}$, cancer, rheumatic disease)

On $\neq$ off treatment

TACQOL Healthy $\neq$ chronic diseases, medical treatment

YQOL-R

Healthy $\neq$ chronic health condition
Construct validity

Factor analysis, correlation with instruments, preknown information, clinical symptoms, etc.

Most items correlate most highly with the sub-domain in which they had originally been placed (factor analysis). Differentiates in predicted direction between four groups of teenagers known to differ in their current health status

Basic conceptual framework is supported by factor analysis. Emotional discomfort correlates ( $r$ 0.63) with Baltimore How I Feel scale. Selfesteem correlated with CHQ satisfaction $(r 0.58)$. Limitation of activity correlates ( $r$ 0.53) with CHQ physical functioning scale

Presence of diabetes symptoms and concerns correlated with lower physical and psychosocial functioning of CHQ. In asthma 7 of 9 dimensions of the CHQ correlate with the Child Health Assessment Questionnaire. The CHQ correlated with the KINDL on the domains: physical, emotional, and self esteem

CHQ scales loaded highest on their hypothesized vector (factor analysis). Strong correlations between CHQ bodily pain and HUI 2/HUI 3 pain scales ( $r$ 0.51-0.60), and between CHQ mental health and HUI 2/HUI 3 emotion $(r 0.53-0.64)$. CHQ is correlated with symptom severity in Juvenile Chronic Arthritis (JCA) and symptom activity in asthma

Severity of sickle cell disease correlates with mean physical summary score. All correlation coefficients between CHQ domains and the visual analog scale rating of the child's health are positive and significant

Differentiates between levels of severity of asthma and arthritis. Correlations were highest with dimensions of HRQL measures evaluating similar concepts

Moderate correlation with clinical rating. Negatively correlated with days hospitalized, days absent from school, and days in bed

HUI $2 / 3$ pain correlates with CHQ bodily pain $(r 0.51-0.60)$. HUI 2 mobility correlates with CHQ physical functioning $(r 0.45-0.58)$. HUI $2 / 3$ emotion correlates with CHQ mental health $(r$ 0.53-0.64). Important differences in HRQL scores between patients, parents, and physicians

Strong correlation with KIDSCREEN-27 ( $r$ 0.63-0.96). High correlation with KINDL for dimensions assessing similar constructs $(r$ 0.51-0.68)

Strong correlation with KIDSCREEN-52 ( $r$ 0.63-0.96). Moderate to high correlation with other HRQL measures assessing similar constructs $(r$ $0.36-0.63)$. Correlation with psychosomatic complaints $(r 0.52)$

KINDL physical correlates with CHQ physical scales $(r-.38-0.55)$. KINDL emotional and self esteem correlates with CHQ mental health and self esteem $(r$ 0.41-0.62). Factor solution in line with the original subscales. Strong correlation with the Short Form-36 for mental health and physical functioning ( $r$ 0.53-0.86)

Most PedsQL items load most highly on their conceptually derived scale (factor analysis). Significant correlations in the expected direction with the PedsMIDAS total score (headache-specific measure of disability). Negatively correlated with the GMFCS score. Discriminates between children with extremity fractures and children with traumatic brain injury. Related to indicaters of morbidity and illness burden. Change over time as a result of clinical intervention

Almost all items (93\%) loaded higher on their own factors than on other factors. Correlation between TACQOL and KINDL ( $r$ 0.24-0.60). Mean correlation between contextual similar domains of the EuroQoL and the TACQOL was -0.55)

All scales correlate highly with the scales of the KINDL. Low correlation with two measures assessing different constructs: the Functional Disability Inventory and the Children's Depression Inventory 


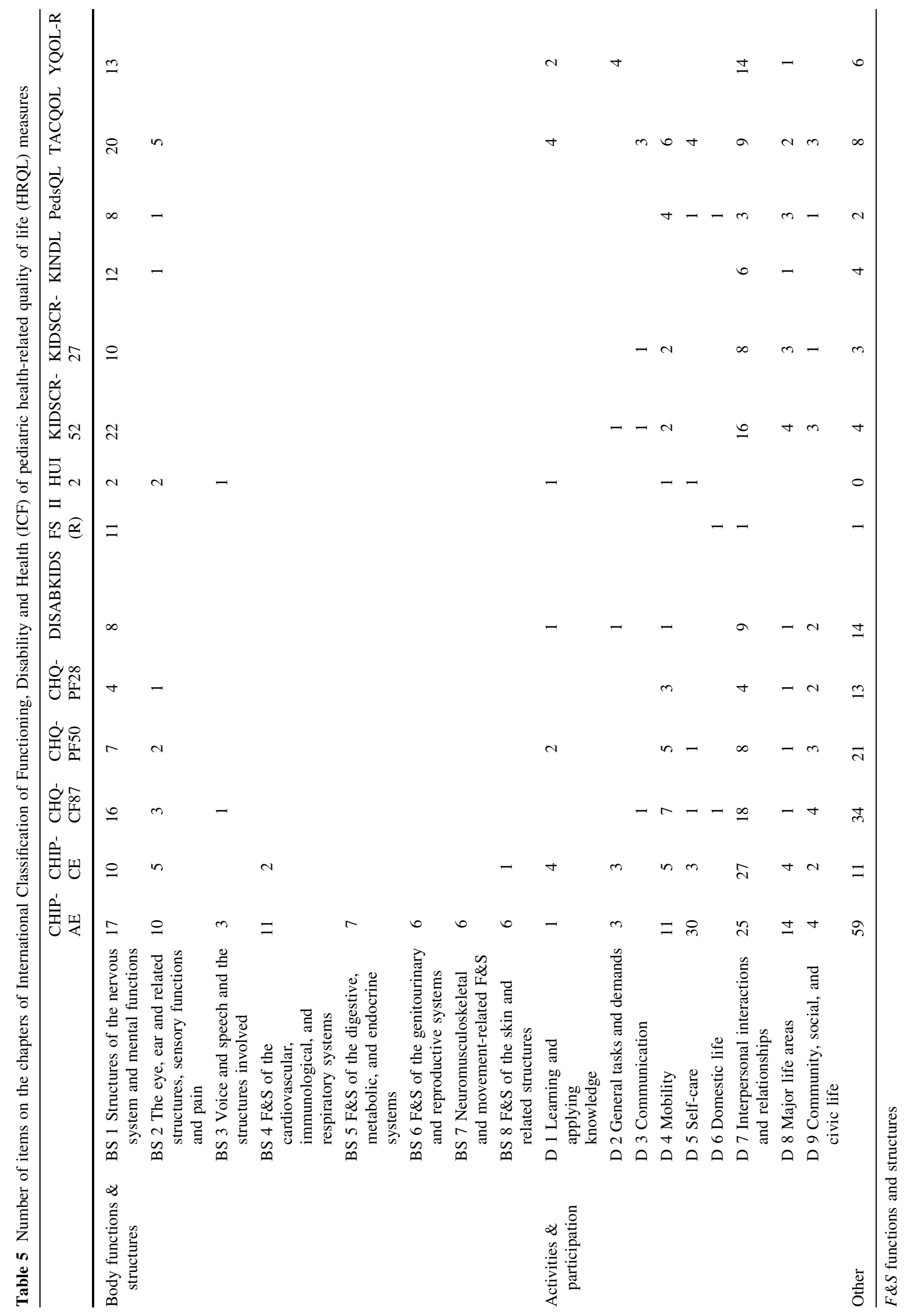


Dutch is the language of interest of the research group. Another reason was that for comparison of the content of the measures the researcher should fully understand the items. Two French questionnaires, the Vecú de Santé Perçué Adolescent (VSP-A) and the Duke Health Profile (DUKE HP), were therefore excluded.

The number of available references for each measure is quite variable in this review. Some measures were assessed on the basis of only one reference, whereas other measures have 26 references for assessment. More references lead to a more reliable assessment of the psychometric properties of the measure. Unfortunately, internal consistency was not reported for HUI 2, no test-retest was reported for KINDL, and no content validity was reported for KIDSCREEN 52. It is questionable whether the reported information on content validity - the ability to discriminate between health and disease-is really that interesting in a trauma population. It seems much more important for an HRQL measure to distinguish between subjects with injuries of different severity levels. Unfortunately, this information is lacking in current literature for all the included HRQL measures. In fact, PedsQL 4.0 is the only HRQL measure validated in children after trauma at all [10]. Comparison of general characteristics and covering ICF chapters of activities and participation are not influenced by the number of references.

Strength of this review is comparison of HRQL measures on four levels: age range, reliability, validity, and content related to ICF. Earlier reviews on generic HRQL measures in children report general characteristics and psychometric properties [97, 98, 100-104]. The age range for which the measure is suitable, domain titles, number of items, and time needed to complete the questionnaire is often described. Internal consistency of the measures is reported by Ravens-Sieberer et al., Willis et al., Rajmil et al., and Connolly et al., and the last two also reported test-retest reliability [97, 101-103]. Only Rajmil et al. report on the content of the measures [102]. They placed the dimensions of the questionnaires in one of three domains: physical, psychological, or social. No previous review compares HRQL measures for children on all four levels looked at in our review. An interesting concept that was considered as fifth level in this review was the responsiveness of the measure. Terwee et al. divided responsiveness of HRQL instruments into three categories: (1) the ability to detect change in general, (2) the ability to detect clinically important change, and (3) the ability to detect real changes in the concept being measured [105]. They also eliminated 31 measures of responsiveness after an extensive literature search.

All items of HRQL measures were placed into the chapters of ICF domains. This provided a clear overview of the content of the measures related to ICF. Most measures covered the chapters of activities and participation much better than the chapters of body functions \& structures. This implies that in children, activities and participation are considered of more importance for HRQL than are body functions \& structures. Sometimes placement of an item was difficult, because multiple interpretations of the item were possible. Especially when it came to cognitive functions, distinction between body functions and activities was often not very clear. Furthermore, many items could not be placed in one of the ICF chapters. The constructs measured by these items were often too broad to be placed in one chapter. Also, items about personal or environmental factors, feelings, and emotions could not be placed in the chapters of the three ICF domains. The fact that many items could not be placed in ICF implies that HRQL is a broader concept than health status as defined by ICF.

\section{Conclusion}

Based on the results of this review, DISABKIDS, KIDSCREEN 52, and PedsQL4.0 seem to be most suitable to measure HRQL of children over the long term after major trauma. They cover a large age range, have good psychometric properties, and cover the ICF content substantially.

Acknowledgements The authors thank Maureen Bult, MSc, for her contribution in placing the items of HRQL measures in the ICF chapters. This research was supported by funding of the "Wilhelmina Kinderziekenhuis (WKZ) Fonds", the Netherlands.

Open Access This article is distributed under the terms of the Creative Commons Attribution Noncommercial License which permits any noncommercial use, distribution, and reproduction in any medium, provided the original author(s) and source are credited.

\section{References}

1. Vademecum of health statistics of the Netherlands: 2003. Statistics Netherlands, Ministry of Health, Welfare and Sports, Voorburg/Heerlen, The Netherlands (2004).

2. O'Neale Roach, J. (2001). Injuries kill over 20,000 children a year in developed countries. Biomedical Journal, 322, 317.

3. Suominem, P., Kivioja, A., Ohman, J., Korpela, R., Rintala, R., \& Olkkola, K. T. (1998). Severe and fatal childhood trauma. Injury, 29(6), 425-430.

4. Polinder, S., Meerding, W. J., Toet, H., Mulder, S., Essink-Bot, M. L., \& van Beeck, E. F. (2005). Prevalence and prognostic factors of disability after childhood injury. Pediatrics, 116, 810 817.

5. Schalamon, J., Bismarck, S., Schober, P. H., \& Hollwarth, M. E. (2003). Multiple trauma in pediatric patients. Pediatric Surgical Interventions, 19, 417-423.

6. Evans, S. A., Airey, M. C., Chell, S. M., Connelly, J. B., Rigby, A. S., \& Tennant, A. (2003). Disability in young adults following major trauma: 5 year follow-up of survivors. BioMed Central Public Health, 3, 8. 
7. Letts, M., Davidson, D., \& Lapner, P. (2002). Multiple trauma in children: Predicting outcome and long-term results. Canadian Journal of Surgery, 45(2), 126-131.

8. Hu, X., Wesson, D. E., Logsetty, S., \& Spence, L. J. (1994). Functional limitations and recovery in children with severe trauma: A one-year follow-up. The Journal of Trauma, 37(2), 209-213.

9. Wesson, D. E., Williams, J. I., Spence, L. J., Filler, R. M., Armstrong, P. F., \& Pearl, R.H. (1989). Functional outcome in pediatric trauma. The Journal of Trauma, 29(5), 589-592.

10. McCarthy, M. L., MacKenzie, E. J., Durbin, D. R., Aitken, M. E., Jaffe, K. M., Paidas, C. N., Slomine, B. S., Dorsch, A. M., Berk, R. A., Christensen, J. R., \& Ding, R. (2005). The Pediatric Quality of Life Inventory: An evaluation of its reliability and validity for children with traumatic brain injury. Archives of Physical Medicine and Rehabilitation, 86, 1901-1908.

11. Ravens-Sieberer, U., Patrick, P. B., Benz, B., Calaminus, G., Flechtner, H., Melchers, P., Patrick, P., Schafer, B., Suhr, L., Schrod, L., Ure, B., \& Willadino-Braga, L. (2002). Quality of life in children with traumatic brain injury: Basic issues, assessment, and recommendations. Restorative Neurology and Neuroscience, 20, 151-159.

12. Stacin, T., Drotar, D., Taylor, H. G., Yeates, K. O., Wade, S. L., \& Minich, N. M. (2002). Health-related quality of life of children and adolescents after traumatic brain injury. Pediatrics, 109, E34.

13. van der Sluis, C. K., Kingma, J., Eisma, W. H., \& Duis ten, H. J. (1997). Pediatric polytrauma: Short-term and long-term outcomes. The Journal of Trauma: Injury, Infection, and Critical Care, 43, 501-506.

14. Holbrook, T. L., Hoyt, D. B., Coimbra, R., Potenza, B., Size, M. J., Sack, M. J., \& Anderson, J. P. (2007). Trauma in adolescents causes long-term marked deficits in quality of life: Adolescent children do not recover preinjury quality of life of function up to two years post-injury compared to national norms. The Journal of Trauma, 62(3), 577-583.

15. WHOQOL Group. (1995). The World Health Organization Quality of Life assessment (WHOQOL): Position paper from the World Health Organization. Social Science \& Medicine, 41, 1403-1409.

16. World Health Organization. (2001). International Classification of Functioning, Disability and Health: ICF. Geneva, Switzerland: World Health Organization.

17. Bland, J. M., \& Altman, D. G. (1997). Cronbach's $\alpha$. Biomedical Journal, 314, 572.

18. Landis, J. R., \& Koch, G. G. (1977). The measurement of observer agreement for categorical data. Biometrics, 33(1), 159-174.

19. Rajmil, L., Serra-Sutton, V., Alonso, J., Starfield, B., Riley, A. W., \& Vazquez, J. R., \& The research group for the Spanish version of the CHIP-AE. (2003). The Spanish version of the Child Health and Illness Profile-Adolescent Edition (CHIPAE). Quality of Life Research, 12, 303-313.

20. Starfield, B., Riley, A. W., Green, B. F., Ensminger, M. E., Ryan, S. A., Kelleher, K., Kim-Harris, S., Johnston, D., \& Vogel, K. (1995). The Adolescent Child Health and Illness Profile. A Population-Based Measure of Health. Medical Care, 33, 210217.

21. Starfield, B., Berger, M., Ensminger, M., Riley, A., Ryan, S., Green, B., McGauhey, P., Skinner, A., \& Kim, S. (1993). Adolescent health status measurement: Development of the Development of the Child Health and Illness Profile. Pediatrics, 91, 430-435.

22. Riley, A. W., Forrest, C. B., Rebok, G. W., Starfield, B., Green, B. F., Robertson, J. A., \& Friello, P. (2004). The child report form of the CHIP-Child Edition, reliability and validity. Medical Care, 42, 221-231.
23. Riley, A. W., Forrest, C. B., Starfield, B., Rebok, G. W., Robertson, J. A., \& Green, B. F. (2004). The parent report form of the CHIP-Child Edition: Reliability and validity. Medical Care, 42, 210-220.

24. Raat, H., Mangunkusumo, R. T., Landgraf, J. M., Kloek, G., \& Brug, J. (2007). Feasibility, reliability, and validity of adolescent health status measurement by the Child Health Questionnaire Child Form (CHQ-CF): Internet administration compared with the standard paper version. Quality of Life Research, 16, 675685.

25. Helseth, S., Lund, T., \& Christophersen, K. A. (2006). Healthrelated quality of life in a Norwegian sample of healthy adolescents: Some psychometric properties of CHQ-CF87-N in relation to KINDL-N. Journal of Adolescent Health, 38, 416425.

26. Norrby, U., Nordholm, L., Andersson-gare, B., \& Fasth, A. (2006). Health-related quality of life in children diagnosed with asthma, diabetes, juvenile chronic arthritis or short stature. Acta Pediatrica, 95, 450-456.

27. Norrby, U., Nordholm, L., \& Fasth, A. (2003). Reliability of the Swedish version of Child Health Questionnaire. Scandinavian Journal of Rheumatology, 32, 101-107.

28. Raat, H., Landgraf, J. M., Bonsel, G. J., Gemke, R. J., \& EssinkBot, M. L. (2002). Reliability and validity of the Child Health Questionnaire-Child Form (CHQ-CF87) in a Dutch adolescent population. Quality of Life Research, 11, 575-581.

29. Waters, E. B., Salmon, L. A., Wake, M., Wright, M., \& Hesketh, K. D. (2001). The health and well-being of adolescents: A school based population study of the self-report Child Health Questionnaire. The Journal of Adolescent Health, 29, 140-149.

30. Wake, M., Hesketh, K., \& Cameron, F. (2000). The Child Health Questionnaire in children with diabetes: Cross-sectional survey of parent and adolescent-reported functional health status. Diabetic medicine, 17, 700-707.

31. Rentz, A. M., Matza, L. S., Secnik, K., Swensen, A., \& Revicki, D. A. (2005). Psychometric validation of the Child Health Questionnaire (CHQ) in a sample of children and adolescents with attention-deficit/hyperactivity disorder. Quality of Life Research, 14, 719-734.

32. Sung, L., Greenberg, M. L., Doyle, J. J., Young, N. L., Ingber, S., Rubenstein, J., Wong, J., Samanta, T., McLimont, M., \& Feldman, B. M. (2003). Construct validation of the Health Utilities Index and the Child Health Questionnaire in children undergoing cancer chemotherapy. British Journal of Cancer, 88, 1185-1190.

33. Wake, M., Salmon, L., \& Reddihough, D. (2003). Health status of Australian children with mild to severe cerebral palsy: Crosssectional survey using the Child Health Questionnaire. Developmental Medicine and Child Neurology, 45, 194-199.

34. Warschburger, P., Landgraf, J. M., Petermann, F., \& Freidel, K. (2003). Health-related quality of life in children assessed by their parents: Evaluation of the psychometric properties of the CHQ-PF50 in two German clinical samples. Quality of Life Research, 12, 291-301.

35. Raat, H., Bonsel, G. J., Essink-Bot, M. L., Landgraf, J. M., \& Gemke, R. J. B. J. (2002). Reliability and validity of comprehensive health status measures in children: The Child Health Questionnaire in relation to the Health Utilities Index. Journal of Clinical Epidemiology, 55, 67-76.

36. Andersson Gare, B. A., Ruperto, N., Berg, S., Hagelberg, S., Jonsson, N. O., Magnusson, B., Martinell, J., Erling, A., \& Landgraf, J. M. (2001). The Swedish version of the Childhood Health Assessment Questionnaire (CHAQ) and the Child Health Questionnaire (CHQ). Clinical and Experimental Rheumatology, 19, S146-S150.

37. Foeldvari, I., Ruperto, N., Dressler, F., Hafner, R., Kuster, R. M., Michels, H., Minden, K., Schauer-Petrowskaja, C., 
Bullinger, M., Landgraf, J. M., \& Huppertz, H. I. (2001). The German version of the Childhood Health Assessment Questionnaire (CHAQ) and the Child Health Questionnaire (CHQ). Clinical and Experimental Rheumatology, 19, S71-S75.

38. Hofer, M., Ruperto, N., Saurenmann, R., Sauvain, M. J., Huppertz, H. I., Landgraf, J. M., \& Prieur, A. M. (2001). The Swiss German and Swiss French versions of the Childhood Health Assessment Questionnaire (CHAQ) and the Child Health Questionnaire (CHQ). Clinical and Experimental Rheumatology, 19, S151-S157.

39. Huemer, C., Ruperto, N., Huemer, M., Sailer-Hoeck, M., Kaulfersch, W., Schwarz, R., Rettenbacher, A., Kenzian, H., Artacker, G., Pilz, I., Bernecker, M., Huppertz, H. I., \& Landgraf, J. M. (2001). The Austrian version of the Childhood Health Assessment Questionnaire (CHAQ) and the Child Health Questionnaire (CHQ). Clinical and Experimental Rheumatology, 19, S15-S19.

40. de Inocencio, J., Garcia-Consuegra, J., Merino, R., Calvo, I., Garcia, J. J., \& Ruperto, N. (2001). The European Spanish version of the Childhood Health Assessment Questionnaire (CHAQ) and the Child Health Questionnaire (CHQ). Clinical and Experimental Rheumatology, 19, S141-S145.

41. Joos, R., Ruperto, N., Wouters, C., Boven, K., Raat, H., Landgraf, J. M., \& Veys, E. M. (2001). The Belgian-Flemish version of the Childhood Health Assessment Questionnaire (CHAQ) and the Child Health Questionnaire (CHQ). Clinical and Experimental Rheumatology, 19, S20-S24.

42. Melo-Gomes, J. A., Ruperto, N., Canhao, H., Fonseca, J. E., Quintal, A., Salgado, M., \& Santos, M. J. (2001). The Portugese version of the Childhood Health Assessment Questionnaire (CHAQ) and the Child Health Questionnaire (CHQ). Clinical and Experimental Rheumatology, 19, S126-S130.

43. Nielsen, S., Ruperto, N., Herlin, T., \& Pedersen, F. K. (2001). The Danish version of the Childhood Health Assessment Questionnaire (CHAQ) and the Child Health Questionnaire (CHQ). Clinical and Experimental Rheumatology, 19, S50-S54.

44. Nugent, J., Ruperto, N., Grainger, J., Machado, C., Sawney, S., Baildam, E., Davidson, J., Foster, H., Hall, A., Hollingworth, P., Sills, J., Venning, H., Walsh, J. E., Landgraf, J. M., Roland, M., Woo, P., \& Murray, K. J. (2001). The Brittish version of the Childhood Health Assessment Questionnaire (CHAQ) and the Child Health Questionnaire (CHQ). Clinical and Experimental Rheumatology, 19, S163-S167.

45. Pelkonen, P., Ruperto, N., Honkanen, V., Hannula, S., Savolainen, A., \& Lahdenne, P. (2001). The Finnish version of the Childhood Health Assessment Questionnaire (CHAQ) and the Child Health Questionnaire (CHQ). Clinical and Experimental Rheumatology, 19, S55-S59.

46. Pouchot, J., Ruperto, N., Lemelle, I., Sommelet, D., Grouteau, E., David, L., Duquesne, A., Deslandre, C. J., Kone Paut, I., Pillet, P., Goumy, L., Barbier, C., Guyot, M. H., Mazingue, F., Gandon Laloum, S., Fischbach, M., Quartier, P., Guyot, C., Jean, S., Gall le, E., Plouvier, E., Bost, M., de Lumley, L., LePlege, A., Larbre, J. P., Guillemin, F., Coste, J., Landgraf, J. M., \& Prieur, A. M. (2001). The French version of the Childhood Health Assessment Questionnaire (CHAQ) and the Child Health Questionnaire (CHQ). Clinical and Experimental Rheumatology, 19, S60-S65.

47. Pratsidou-Gertsi, P., Vougiouka, O., Tsitsami, E., Ruperto, N., Siamopoulou-Mavridou, A., Dracou, C., Daskas, I., Trachana, M., Aleleou, V., \& Kanakoudi-Tsakalidou, F. (2001). The Greek version of the Childhood Health Assessment Questionnaire (CHAQ) and the Child Health Questionnaire (CHQ). Clinical Experimental Rheumatology, 19, S76-S80.

48. Ruperto, N., Ravelli, A., Pistorio, A., Malattia, C., Viola, S., Cavuto, S., Alessio, M., Alpigiani, M. G., Buoncompagni, A., Corona, F., Cortis, F., Falcini, F., Gerloni, V., Lepore, L.,
Sardella, M. L., Strano, C. G., Zulian, F., Gado-West, L., Tortorelli, A., Fantini, F., \& Martini, A. (2001). The Italian version of the Childhood Health Assessment Questionnaire (CHAQ) and the Child Health Questionnaire (CHQ). Clinical and Experimental Rheumatology, 19, S91-S95.

49. Selvaag, A. M., Ruperto, N., Asplin, L., Rygg, M., Landgraf, J. M., Forre, O., \& Flato, B. (2001). The Norwegian version of the Childhood Health Assessment Questionnaire (CHAQ) and the Child Health Questionnaire (CHQ). Clinical and Experimental Rheumatology, 19, S116-S120.

50. Wulffraat, N., Net van der, J. J., Ruperto, N., Kamphuis, S., Prakken, B. J., Cate ten, R., Soesbergen van, R. M., Rossum van, M. A., Raat, H., Landgraf, J. M., \& Kuis, W., (2001). Pediatric rheumatology international trials organisation. The Dutch version of the Childhood Health Assessment Questionnaire (CHAQ) and the Child Health Questionnaire (CHQ). Clinical and Experimental Rheumatology, 19, S111-S115.

51. Asmussen, L., Olson, L. M., Grant, E. N., Landgraf, J. M., Fagan, J., \& Weiss, K. B. (2000). Use of the Child Health Questionnaire in a sample of moderate and low-income innercity children with asthma. American Journal of Respiratory and Critical Care Medicine, 162, 1215-1221.

52. Nixon-Speechley, K., Maunsell, E., Desmeules, M., Schanzer, D., Landgraf, J. M., Feeny, D. H., \& Barrera, M. E. (1999). Mutual concurrent validity of the Child Health Questionnaire and the Health Utilities Index: An exploratory analysis using survivors of childhood cancer. International Journal of Cancer, $12,95-105$

53. Landgraf, J. M., Maunsell, E., Nixon-Speechley, K., Bullinger, M., Campbell, S., Abetz, L., \& Ware, J. E. (1998). CanadianFrench, German and UK versions of the Child Health Questionnaire: Methodology and preliminary item scaling results. Quality of Life Research, 7, 433-445.

54. Raat, H., Botterweck, A. M., Landgraf, J. M., Hoogeveen, W. C., \& Essink-Bot, M. L. (2005). Reliability and validity of the short form of the Child Health Questionnaire for parents (CHQPF28) in large random school based and general population samples. Journal of Epidemiology and Community Health, 59, $75-82$.

55. Woods-Byrne, M., \& Honig, J. (2005). Psychometrics of Child Health Questionnaire parent short form (CHQ-28) used to measure quality of life in HIV-infected children on complex anti-retroviral therapy. Quality of Life Research, 14, 1769-1774.

56. Georgalas, C., Tolley, N., \& Kanagalingam, J. (2004). Measuring quality of life in children with adenotonsillar disease with the Child Health Questionnaire: A first U.K. Study. Laryngoscope, 114, 1849-1855.

57. Panepinto, J. A., O’Mahar, K. M., DeBaun, M. R., Rennie, K. M., \& Scott, J. P. (2004). Validity of the Child Health Questionnaire for use in children with sickle cell disease. Journal of Pediatric Hematology and Oncology, 26, 574-578.

58. Simeoni, M. C., Schmidt, S., Muehlan, H., Debensason, D., Bullinger, M. \& DISABKIDS group. (2007) Field testing of a European quality of life instrument for children and adolescents with chronic conditions: The 37-item DISABKIDS chronic generic module. Quality of Life Research, 16(5), 881-893.

59. Schmidt, S., Debensason, D., Muhlan, H., Petersen, C., Power, M., Simeoni, M. C., Bullinger, M \& the European DISABKIDS group. (2006) The DISABKIDS generic quality of life instrument showed cross-cultural validity. Journal of clinical epidemiology, 59(6), 587-598.

60. Post, M. W. M., Kuyvenhoven, M. M., Verheij, T. J. M., de Melker, R. A., \& Hoes, A. W. (1998). De Nederlandse 'Functional Status II(R)': Een vragenlijst voor het meten van de functionele gezondheidstoestand van kinderen. Nederlands $t i$ jdschrift voor geneeskunde, 142, 2675-2679. 
61. Stein, R. E. K., \& Jessop, D. J. (1990). Functional Status II(R), a measure of child health status. Medical care, 28(11), 10411055.

62. Fu, L., Talsma, D., Baez, F., Bonilla, M., Moreno, B., Ah-Chu, M., Pena, A., Furlong, W., \& Barr, R. D. (2006). Measurement of health-related quality of life in survivors of cancer in childhood in Central America: Feasibility, reliability, and validity. Journal of Pediatric Hematology and Oncology, 28, 331-341.

63. Felder-Puig, R., Frey, E., Sonnleithner, G., Feeny, D., Gadner, H., Barr, R. D., Furlong, W., \& Topf, R. (2000). German crosscultural adaptation of the Health Utilities Index and its application to a sample of childhood cancer survivors. European Journal of Pediatrics, 159, 283-288.

64. Trudel, J. G., Rivard, M., Dobkin, P. L., Leclerc, J. M., \& Robaey, P. (1998). Psychometric properties of the Health Utilities Index Mark 2 system in pediatric oncology patients. Quality of Life Research, 7, 421-432.

65. Robitail, S., Simeoni, M. C., Erhart, M., Ravens-Sieberer, U., Bruil, J., Auquier, P., \& the European Kidscreen Group. (2006) Validation of the European proxy KIDSCREEN-52 pilot test health-related quality of life questionnaire: First results. Journal of Adolescent Health, 39, 596.e1-596.e10.

66. Ravens-Sieberer, U., Gosch, A., Rajmil, L., Erhart, M., Bruil, J., Duer, W., Auquier, P., Power, M., Abel, T., Czemy, L., Mazur, J., Czimbalmos, A., Tountas, Y., Hagquist, C., Kilroe, J., Fuerth, K., Robitail, S., Simeoni, M., Orbicini, D., von Rueden, U., Dimitrakaki, C., Detmar, S., Verrips, E., Mierzejewska, E., Berra, S., Tebe, C., Bisegger, C., Cloetta, B., \& Atherton, C. (2005). KIDSCREEN-52 quality-of-life measure for children and adolescents. Expert Review of Pharmacoeconomics and Outcome Research, 5(3), 353-364.

67. Ravens-Sieberer, U., Auquier, P., Erhart, M., Gosch, A., Rajmil, L., Bruil, J., Power, M., Duer, W., Cloetta, B., Czemy, L., Mazur, J., Czimbalmos, A., Tountas, Y., Hagquist, C., Kilroe, J., $\&$ the European KIDSCREEN group. (2007) The KIDSCREEN27 quality of life measure for children and adolescents: Psychometric results from a cross-cultural survey in 13 European countries. Quality of Life Research, 16(8), 1347-1356.

68. Robitail, S., Ravens-Sieberer, U., Simeoni, M. C., Rajmil, L., Bruil, J., Power, M., Duer, W., Cloetta, B., Czemy, L., Mazur, J., Czimbalmos, A., Tountas, Y., Hagquist, C., Kilroe, J., Auquier, P., \& the KIDSCREEN group. Testing the structural and crosscultural validity of the KIDSCREEN-27 quality of life questionnaire. Quality of Life Research, 16, 1335-1345.

69. Wee, H. L., Ravens-Sieberer, U., Erhart, M., \& Li, S. C. (2007). Factor structure of the Singapore English version of the KINDL children quality of life questionnaire. Health and Quality of Life Outcomes, 5, 4.

70. Helseth, S., \& Lund, T. (2005). Assessing health-related quality of life in adolescents: Some psychometric properties of the first Norwegian version of KINDL. Scandinavian Journal of Caring Sciences, 19, 102-109.

71. Wee, H. L., Lee, W. W. R., Ravens-Sieberer, U., Erhart, M., \& Li, S. C. (2005). Validation of the English version of the KINDL generic children's health-related quality of life instrument for an Asian population-results from a pilot test. Quality of Life Research, 14, 1193-1200.

72. Ravens-Sieberer, U., \& Bullinger, M. (1998). Assessing healthrelated quality of life in chronically ill children with the German KINDL: First psychometric and content analytical results. Quality of Life Research, 7, 399-407.

73. Laaksonen, C., Aromaa, M., Heinonen, O. J., Suonimen, S., \& Salantera, S. (2007). Paediatric health-related quality of life instrument for primary school children: Cross-cultural validation. Journal of Advanced Nursing, 59(5), 542-550.
74. Varni, J. W., Limbers, C. A., \& Burwinkle, T. M. (2005). How young can children reliably and validly self-report their healthrelated quality of life?: An analysis of 8,591 children across age subgroups with the PedsQL 4.0 generic core scales. Health and Quality of Life Outcomes, 5, 1.

75. Varni, J. W., Limbers, C. A., \& Burwinkle, T. M. (2007). Parent proxy-report of their children's health-related quality of life: An analysis of 13,878 parents' reliability and validity across age subgroups using the PedsQL 4.0 generic core scales. Health and Quality of Life Outcomes, 5, 2.

76. Connelly, M., \& Rapoff, M. A. (2006). Assessing health-related quality of life in children with recurrent headache: Reliability and validity of the PedsQL 4.0 in a pediatric headache sample. Journal of Pediatric Psychology, 31(7), 698-702.

77. Cremeens, J., Eiser, C., \& Blades, M. (2006). Factors influencing agreement between child self-report and parent proxyreports on the Pediatric Quality of Life Inventory 4.0 (PedsQL) generic core scales. Health and Quality of Life Outcomes, 2, 58.

78. Reinfjell, T., Diseth, T. H., Veenstra, M., \& Vikan, A. (2006). Measuring health-related quality of life in young adolescents: Reliability and validity in the Norwegian version of the Pediatric Quality of Life Inventory 4.0 (PedsQL) generic core scales. Health and Quality of Life Outcomes, 4, 61.

79. Varni, J. W., \& Burwinkle, T. M. (2006). The PedsQL as a patient-reported outcome in children and adolescents with attention-deficit/hyperactivity disorder: A population-based study. Health and Quality of Life Outcomes, 4, 26.

80. Varni, J. W., Burwinkle, T. M., Berrin, S. J., Sherman, S. A., Artavia, K., Malcarne, V. L., \& Chambers, H. G. (2006). The PedsQL in pediatric cerebral palsy: Reliability, validity, and sensitivity of the generic core scales and cerebral palsy module. Developmental medicine and child neurology, 48, 442-449.

81. Varni, J. W., Burwinkle, T. M., \& Seid, M. (2006). The PedsQL 4.0 as a school population health measure: Feasibility, reliability, and validity. Quality of Life Research, 15, 203-215.

82. Upton, P., Eiser, C., Cheung, I., Hutchings, H. A., Jenney, M., Maddocks, A., Russell, I. T., \& Williams, J. G. (2005). Measurement properties of the UK-English version of the Pediatric Quality of Life Inventory 4.0 (PedsQL) generic core scales. Health and Quality of Life Outcomes, 3, 22.

83. Upton, P., Maddocks, A., Eiser, C., Barnes, P. M., \& Williams, J. (2005). Development of a measuer of the health-related quality of life of children in public care. Child: Care, Health and Development, 31, 409-415.

84. Bastiaansen, D., Koot, H. M., Bongers, I. L., Varni, J. W., \& Verhulst, F. C. (2004). Measuring quality of life in children referred for psychiatric problems: Psychometric properties of the PedsQL 4.0 generic core scales. Quality of Life Research, 13, 489-495.

85. Felder-Puig, R., Proksch, K., Varni, J. W., Gadner, H., \& Topf, R. (2004). Validation of the German version of the Pediatric Quality of Life Inventory (PedsQL) in childhood cancer patients off treatment and children with epilepsy. Quality of Life Research, 13, 223-234.

86. Varni, J. W., Burwinkle, T. M., Rapoff, M. A., Kamps, J. L., \& Olson, N. (2004). The PedsQL in pediatric asthma: Reliability and validity of the Pediatric Quality of Life Inventory generic core scales and asthma module. Journal of Behavioral Medicine, 27, 297-318.

87. Eiser, C., Vance, Y. H., Horne, B., Glaser, A., \& Galvin, H. (2003). The value of the PedsQLTM in assessing quality of life in survivors of childhood cancer. Child: Care, Health \& Development, 29, 95-102.

88. Varni, J. W., Burwinkle, T. M., Jacobs, J. R., Gottschalk, M., Kaufman, F., \& Jones, K. L. (2003). The PedsQL in type 1 and 
type 2 diabetes: Reliability an validity of the Pediatric Quality of Life Inventory generic core scales and type 1 diabetes module. Diabetes Care, 26, 631-637.

89. Varni, J. W., Burwinkle, T. M., Katz, E. R., Meeske, K., \& Dickinson, P. (2002). The PedsQL in pediatric cancer: Reliability and validity of the Pediatric Quality of Life Inventory generic core scales, multidimensional fatigue scale, and cancer module. Cancer, 94, 2090-2106.

90. Varni, J. W., Seid, M., Smith Knight, T., Burwinkle, T., Brown, J., \& Szer, I. S. (2002). The PedsQL in pediatric rheumatology, reliability, validity, and responsiveness of the Pediatric Quality of Life Inventory generic core scales and rheumatology module. Arthritis and Rheumatism, 46(3), 714-725.

91. Varni, J. W., Seid, M., \& Kurtin, P. S. (2001). PedsQL 4.0: Reliability and validity of the Pediatric Quality of Life Inventory version 4.0 generic core scales in healthy and patient populations. Medical Care, 39(8), 800-812.

92. Stolk, E. A., Busschbach, J. J. V., \& Vogels, T. (2000). Performance of the EuroQoL in children with imperforate anus. Quality of Life Research, 9, 29-38.

93. Verrips, E. G. H., Vogels, A. G., den Ouden, A. L., Paneth, N., \& Verloove-Vanhorrick, S. P. (2000). Measuring health-related quality of life in adolescents: Agreement between raters and between methods of administration. Child: Care, Health and Development, 26, 457-469.

94. Verrips, E. G. H., Vogels, T. G. C., Koopman, H. M., Theunissen, N. C. M., Kamphuis, R. P., Fekkes, M., Wit, J. M., \& Verloove-Vanhorrick, P. (1999). Measuring health-related quality of life in a child population. European Journal of Public Health, 9, 188-193.

95. Vogels, T., Verrips, G. H., Verloove-Vanhorrick, S. P., Fekkes, M., Kemphuis, R. P., Koopman, H. M., Theunissen, N. L., \& Wit, J. M. (1998). Measuring health-related quality of life in children: The development of the TACQOL parent form. Quality of Life Research, 7, 457-465.
96. Patrick, D. L., Edwards, T. C., \& Topolski, T. D. (2002). Adolescent quality of life, part II: Initial validation of a new instrument. Journal of Adolescence, 25(3), 287-300.

97. Willis, C. D., Gabbe, B. J., Butt, W., \& Cameron, P. A. (2006). Assessing outcomes in paediatric trauma populations. Injury, International Journal of the Care of the Injured, 37, 1185-1196.

98. Eiser, C., \& Morse, R. (2001). The measurement of quality of life in children: Past and future perspectives. Developmental and Behavioural Sediatrics, 22(4), 248-256.

99. Van Beeck, E. F., Larsen, C. F., Lyons, R. A., Meerding, W. J., Mulder, S., \& Essink-Bot, M. L. (2007). Guidelines for the conduction of follow-up studies measuring injury-related disability. The Journal of Trauma: Injury, Infection, and Critical Care, 62, 534-550.

100. Raat, H., Mohangoo, A. D., \& Grootenhuis, M. A. (2006). Pediatric health-related quality of life questionnaires in clinical trials. Current Opinion in Allergy and Clinical Immunology, 6, 180-185.

101. Ravens-Sieberer, U., Erhart, M., Wille, N., Wetzel, R., Nickel, J., \& Bulliger, M. (2006). Generic health-related quality of life assessment in children and adolescents. Pharmacoeconomics, 24(12), 1199-1220.

102. Rajmil, L., Herdman, M., Fernandez de Sanmamed, M. J., Detmar, S., Bruil, J., Ravens-Sieberer, U., Bullinger, M., Simeoni, M. C., \& Auquier, P. (2004). Generic health-related quality of life instruments in children and adolescents: A qualitative analysis of content. Journal of Adolescent Health, 34, 37-45.

103. Connolly, M. A., \& Johnson, J. A. (1999). Measuring quality of life in paediatric patients. Pharmacoeconomics, 16(6), 605-625.

104. Spieth, L. E., \& Harris, C. V. (1996). Assessment of healthrelated quality of life in children and adolescents: An integrative review. Journal of Pediatric Psychology, 21(2), 175-193.

105. Terwee, C. B., Dekker, F. W., Wiersinga, W. M., Prummel, M. F., \& Bossuyt, P. M. (2003). On assessing responsiveness of health-related quality of life instruments: Guidelines for instrument evaluation. Quality of Life Research, 12, 349-362. 